\title{
Performance of Submerged Membrane Bioreactor Combined with Powdered Activated Carbon Addition for the Treatment of an Industrial Wastewater
}

\author{
Tri Widjaja ${ }^{1}$, Ali Altway ${ }^{1}$, and Soeprijanto ${ }^{1}$
}

\begin{abstract}
Membrane technology is one of the alternative solutions to overcome industrial wastewater treatment developed nowadays. The addition of PAC (Powdered Activated Carbon) in the activated sludge using Submerged Membrane Adsorption Hybrid Bioreactor (SMAHBR) is expected to increase the organic material removal. The purpose of this study was to determine the performance of submerged membrane bioreactor and activated carbon adsorption capacity of organic materials in wastewater. This study used SIER (Surabaya Industrial Estate Rungkut Surabaya, Indonesia) waste as activated sludge operated at Mixed Liquor Suspended Solid (MLSS) concentrations of 8000 and $15000 \mathrm{mg} / \mathrm{l}$, and Chemical Oxygen Demand (COD) concentrations of $1500,2500 \mathrm{mg} / \mathrm{l}$, Sludge Retention Time (SRT) of 10;20; and 30 days and activated carbon variables of $0 \% ; 2.5 \% ; 5 \% ; 7.5 \% ; 10 \%$. The results showed that the fouling potential occurred at high MLSS where the COD removal occurred at PAC addition of $10 \%$ reaching 91.86\%. High Soluble Microbial Product (SMP) accumulation $( \pm 10 \mathrm{mg} / \mathrm{l})$ occurred in short SRT and high MLSS concentration. PAC addition resulted in decreased microorganisms in the reactor and better effluent of SMAHBR, as a result, the performance of the submerged membrane bioreactor would be restored.
\end{abstract}

Keywords - Submerged Membrane Adsorption Hybrid Bioreactor, Powdered Activated Carbon

\section{INTRODUCTION}

$\mathrm{T}$ he rapid increase of industrial development in the globalization era leads to increase in wastewater effluent resulting in environmental problems. Biological wastewater treatment is one of the treatment choices. Generally, this treatment uses biological aerobic system in the conventional activated sludge. This process uses microorganisms to degrade organic materials contained in wastewater. However, this process has some disadvantages in that it takes a long time and requires large area to separate sludge from water in the secondary sedimentation tank as well as requires very specific operating conditions, especially the organic loading and the concentrations of microorganisms. Liu (2003) stated that using the conventional activated sludge could remove COD about $93-96 \%$ of domestic wastewater. Therefore, to solve these problems, membrane technology, in this case submerged membrane bioreactor or SMBR, is used. This bioreactor, consisting of the biological process and membrane filtration, can overcome excessive fluctuations on the influent and effluent quality [15].

${ }^{1}$ Tri Widjaja, Ali Altway, and Soeprijanto are with Department of Chemical Engineering, FTI, Institut Teknologi Sepuluh Nopember, Surabaya, 60111, Indonesia.
Submerged Membrane Bioreactor (SMBR) was an efficient technology for biological wastewater treatment process in which the conventional biomass-effluent separation clarifiers were replaced by microfiltration or ultra filtration modules [3]. They can be broadly defined as systems integrating biological degradation of wastewater with membrane filtration and have proven to be effective in removing organic and inorganic contaminants as well as biological entities. The other advantages of the SMBR over the conventional activated sludge process of wastewater treatment include a small footprint, a low sludge production rate and easy manipulation of the Sludge Retention Time (SRT) [3]. They can be operated at high Mixed Liquor Suspended Solid (MLSS) concentrations because a membrane, rather than gravity sedimentation basin, is used for solid-liquid separation [19].

Nevertheless, SMBR has some problems in regard to the separation processes. One of them is the occurrence of fouling, which is a decomposition process of Soluble Microbial Products (SMP) and organic compounds and biomass that inhibit membrane pores, as a result, the flux permeate decreases toward certain operational time. SMP is a product of microorganism metabolism in bioreactor which can be humic substances, carbohydrates, proteins, fats and other mineral salts [9].

The presence of membrane fouling causes the decrease membrane's performance, so that COD removal was not high [9]. High SRT can decrease permeate flux, because more foulings occur. High concentration of biomass (MLSS) also causes fouling membrane so that decreases permeate flux. The addition of PAC increases the adsorption of low molecular organics and thus reduces the membrane fouling (Ying and Ping, 2006). In the aerobic biological process, the fluctuating waste load leads to the recovery of the microorganisms (as organic soluble decomposer) to take a long time and disturbed process conditions. These conditions lead to reduced ability of microorganisms to degrade which influences significantly on filtration process [10].

To solve these problems, Powdered Activated Carbon (PAC) is added into the SMBR to bind microbial and other organic substances contain in liquid waste so that they can be removed well. Munz and Gori (2007) stated that PAC addition will remove organic substances in membrane which would reduce the possibility of fouling to occur. Activated carbon which represents adsorben is a porous solid, mostly consist of free elements carbon and each covalently bonded. Thus, activated carbon surface is non polar. Besides composition and polarity, pores structure also represent important factor. Pores structure related to surface area. Smaller pores of 
activated carbon means higher surface area, so the adsorption velocity increase. To enhance adsorption velocity, suggested to use activated carbon which has been mashed. Powdered Activated Carbon (PAC) can absorp toxic better than the granular ones because PAC has larger surface area [5].

In particular, PAC addition increases the removal of low molecular weight organics by adsorption, it also acts as a supporting medium for attached bacterial growth and influences the bacterial population [16].

Higher biological activity can be expected by holding PAC in the filtration reactor. This study revealed that the filtrate quality and the performance efficiency enhanced when PAC was introduced into the filtration system [6].

Wastewater treatment system generally applied in industries nowadays is a combination of biological and physical processes. Biological processes use activated sludge processes or bio filter, while physical processes comprise a process of coagulation-flocculation. Meanwhile, another process that can also be used is an adsorption process, which uses activated carbon [13]. To minimize the expenses, it is necessary to combine the two processes that were done by adding the activated carbon to the aeration tank containing activated sludge. The operational process conditions cover sludge concentration as a Mixed Liquor Suspended Solid (MLSS) which are composed of sludge and activated carbon, and Sludge Retention Time (SRT) [7].

The process is based on a bioreactor with a membrane separation and powdered activated carbon. A biofilm could grow on the activated carbon surface and develop a specific population to the degradation of the toxic compound. For the MBR, about $94 \%$ of the COD was removed. It is close to the results obtained by Bouhabila in 1999 for the removal of a synthetic substrate by submerged MBR. SMAHBR performances lead to remove about $96 \%$ of the COD. It is close to the results obtained with the MBR. Activated carbon addition slightly increases the performances of the process [13].

The purpose of this experiments were to study the performance of SMBR system with PAC addition and fouling which contributed to the decrease of membrane performance and to know the influence of PAC addition on the performance of wastewater treatment systems as well as to determine the biological process conditions as a result of concentration of MLSS and COD [4].

\section{MethodOLOGY}

In this experiment used Submerged Membrane Bioreactor. A schematic diagram of submerged membrane bioreactor is shown in Fig. 1. The membrane was made of a hollow fiber polysulfone with an average pore diameter of $0.01 \mu \mathrm{m}$ and membrane filtration area of 1 $\mathrm{m}^{2}$ immersed in a vertical reactor with the outlet located on the top. At the bottom of the reactor is mounted a diffuser to provide air bubbles sprayed from the bottom of the membrane. The specification of membrane module is shown in Table 1. Activated carbon used here was Powdered Activated Carbon (PAC) which was made from coal as shown in Table 2.

\section{A. Experimental Set-Up}

Initial seeding of the bioreactor was accomplished by inoculating the bioreactor with 50 liters of returned acti- vated sludge that was collected from an industrial wastewater treatment plant (SIER). Glucose substrates and nutrients ( $\mathrm{N}$ and $\mathrm{P}$ ) were added to wastewater. It was stopped when MLSS had reached variables (8,000 and $15,000 \mathrm{mg} / \mathrm{L})$. After that, it was continued to acclimatize to the synthetic substrate. At this step, activated sludge was precipitated for 2 hours, then removed and replaced the supernatant with synthetic wastewater, and made an observation of COD. Aeration tank used was equipped with aerator to circulate air through the diffuser which was placed at the bottom of the tank.

Synthetic wastewater was fed continuously into the reactors as a feed. This study used a single active biological sludge reactor unit as a place for membrane separation process. Composition of synthetic wastewater was adjusted to have COD of $1500 \mathrm{mg} / \mathrm{l}$ and $2500 \mathrm{mg} / \mathrm{l}$ and at a ratio of 100:10:1 for the COD: $\mathrm{N}$ and $\mathrm{P}$ as shown in Table 3. To recover the membrane performance it needs to set back flushing for 10 minutes. After that, membrane can be reused.

\section{B. Analytical Methods}

Samples from the reactor and permeate were collected periodically and analyzed. MLSS and COD analysis refer to the Standart Method for Examination of Waste and Wastewater (APHA, 1998). Protein was determined by spectrofotometry UV method. Carbohydrate was determined by Boehringer-Mannheim method using HPLC.

\section{RESULT AND DISCUSSION}

In the bioreactor, organic matter was removed in two stages i.e. biological degradation microorganisms and membrane filtration, which both processes are related. Microorganism metabolism of biological process was influenced by the F/M ratio, which is the amount of substrates used as an energy source for the growth of microorganisms, added to the bioreactor as well as by COD feeding and biomass concentrations. For good sludge conditions, F/M ratio was operated between $0.2-0.6 \mathrm{~kg}$ COD/kg MLSS (Sundstrom and Klei, 1979).

The performance of SMBR is generally associated with the ability of SMBR to degrade organic matter at the different of SRT, MLSS, and COD concentrations.

It is shown in Fig. 2 and Fig. 3 that the biological process was more dominant than the filtration process at MLSS of $8000 \mathrm{mg} / 1$ and $15000 \mathrm{mg} / 1$ for different SRT value. However at MLSS of $15000 \mathrm{mg} / \mathrm{l}$, the biological process was decrease when compared to the conditions at MLSS of $8000 \mathrm{mg} / \mathrm{l}$. This was due to higher ratio of F/M at MLSS of $8000 \mathrm{mg} / 1$ which influenced the microorganism metabolism than that of at MLSS of $15000 \mathrm{mg} / \mathrm{l}$.

\section{A. COD Removal of MLSS (8,000 and 15,000 mg/l) at Various $\operatorname{SRT}(10,20,30$ days)}

The results also showed that the F/M ratio at MLSS of $8000 \mathrm{mg} / 1$ was $0.2 \mathrm{~kg} \mathrm{COD} / \mathrm{kg}$ MLSS.days for the COD of $1500 \mathrm{mg} / 1$ and $0.31 \mathrm{~kg} \mathrm{COD} / \mathrm{kg}$ MLSS.days for the COD of $2500 \mathrm{mg} / \mathrm{l}$. While the F/M ratio at MLSS of $15000 \mathrm{mg} / \mathrm{l}$ was $0.10 \mathrm{~kg} \mathrm{COD} / \mathrm{kg}$ MLSS.days for COD of $1500 \mathrm{mg} / 1$ and $0.17 \mathrm{~kg} \mathrm{COD} / \mathrm{kg}$ MLSS.days for COD of $2500 \mathrm{mg} / \mathrm{l}$. As described above description, it can be said that at MLSS of $8000 \mathrm{mg} / \mathrm{l}$, the $\mathrm{F} / \mathrm{M}$ ratio met the range of $0.2-0.6 \mathrm{~kg} \mathrm{COD} / \mathrm{kg}$ MLSS.days resulting in better microbial growth and good degradation process of organic compounds. 


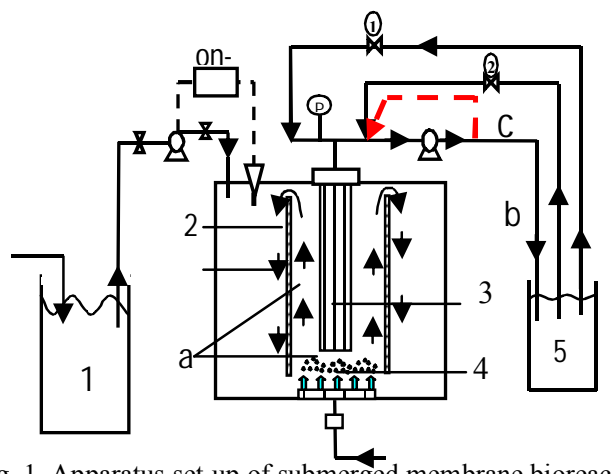

Fig. 1. Apparatus set-up of submerged membrane bioreactor, (1) Synthetic waste feeding tank, (2) Baffle, (3) SMBR, (4) Aerator, (5) Permeate tank, (a) The flow direction, (b) Effluent, (c) The flow direction of Back flushing.

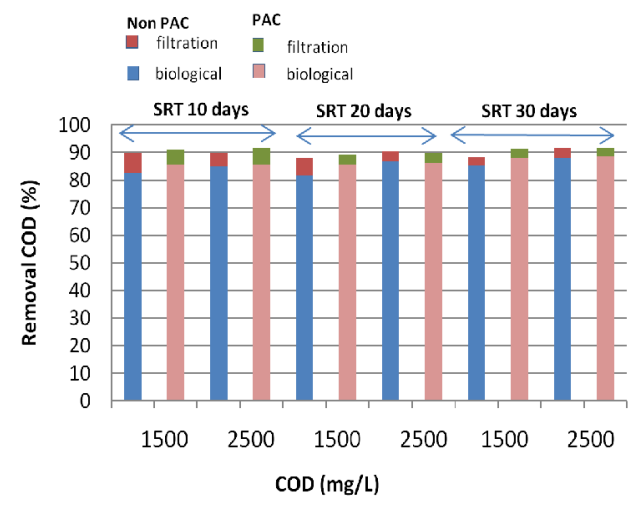

Fig. 2. COD Removal (\%) at MLSS $8000 \mathrm{mg} / 1$

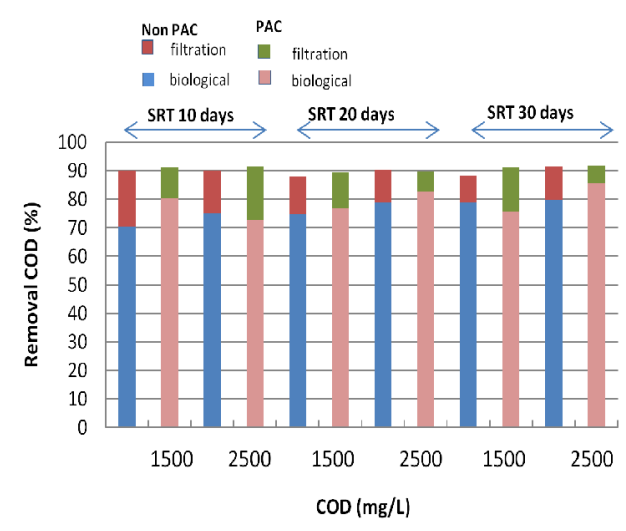

Fig. 3. COD removal (\%) at MLSS $15,000 \mathrm{mg} / \mathrm{l}$

TABLE 1.

SPECIFICATION OF MEMBRANE MODULE

\begin{tabular}{ll}
\hline Membrane type & Ultrafiltration \\
\hline Membrane module & Hollow fiber \\
Membrane material & Polysulfone \\
Surface chemical properties & Hydrofilic \\
Pore size & $0.01 \mu \mathrm{m}$ \\
Outside diameter / inside diameter & $1.20 \mathrm{~mm} / 0.50 \mathrm{~mm}$ \\
Module length & $2 \mathrm{in}$ \\
Number of module & 3 \\
Number of fiber & 85 fiber/module \\
Surface area & $1 \mathrm{~m}^{2}$ \\
\hline
\end{tabular}

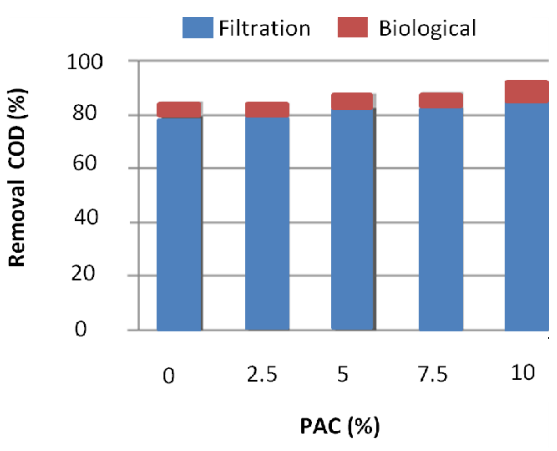

Fig. 4. COD removal of MLSS $(15,000 \mathrm{mg} / \mathrm{l})$ at various concentrations of PAC $(0 ; 2,5 ; 5 ; 7,5 ; 10 \%)$

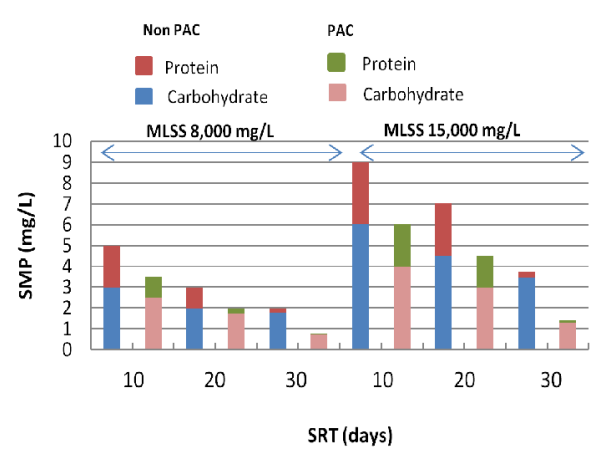

Fig. 5. Comparison of SMP on waste SMAHBR at various MLSS $(8,000$ and $15,000 \mathrm{mg} / \mathrm{l})$ and various SRT(10;20; 30 days) with and without addition of $\mathrm{PAC}$

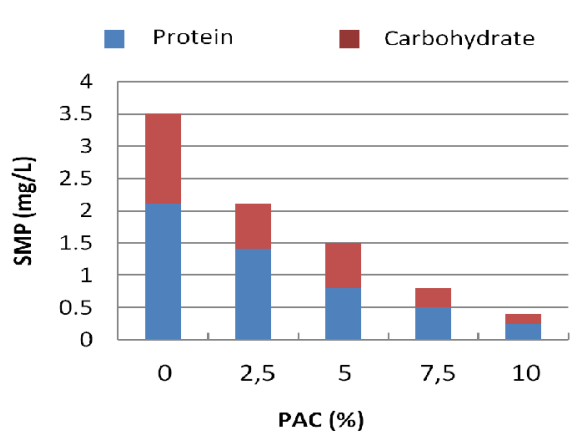

Fig 6. Comparison of SMP in SMAHBR waste of MLSS 15,000 mg/1 at various concentrations of PAC

TABLE 2.

CharaCteristics of POWDERED ACTIVATED CARBon From COALA

\begin{tabular}{lc}
\hline \multicolumn{1}{c}{ Parameter } & Size \\
\hline The total surface area & $1047 \mathrm{~m}^{2} / \mathrm{g}$ \\
Bulk Density Dry & $470 \mathrm{~kg} / \mathrm{m}^{3}$ \\
Particle Size Range & $53-75 \mu \mathrm{m}$ \\
$\mathrm{pH}$ & 7.5 \\
Iodine number $\left(\mathrm{mg} \mathrm{g}^{-1}\right)$ & 1336 \\
Total ash $(\%)$ & 8.3 \\
\hline${ }^{\mathrm{a}}$ Widjaj et al. $(2004)$ &
\end{tabular}


TABLE 3.

COMPOSITION OF SYNTHETIC WASTEWATER

\begin{tabular}{ccc}
\hline Components & $\begin{array}{c}\mathrm{COD} 1500 \\
(\mathrm{mg} / \mathrm{L})\end{array}$ & $\begin{array}{c}\mathrm{COD} 2500 \\
(\mathrm{mg} / \mathrm{L})\end{array}$ \\
\hline Glucose & 882.90 & 1472.00 \\
Glutamate acid & 396.80 & 661.10 \\
$\mathrm{CH}_{3} \mathrm{COONH}_{4}$ & 320.70 & 534.60 \\
$\mathrm{NaHCO}_{3}$ & 343.80 & 343.80 \\
$\mathrm{NH}_{4} \mathrm{Cl}$ & 130.90 & 218.20 \\
$\mathrm{KH}_{2} \mathrm{PO} 4$ & 52.26 & 52.26 \\
$\mathrm{~K}_{2} \mathrm{HPO}_{4}$ & 37.59 & 37.59 \\
$\mathrm{MgSO}_{4} \cdot 7 \mathrm{H}_{2} \mathrm{O}$ & 20.35 & 20.35 \\
$\mathrm{MnSO}_{4} \cdot \mathrm{H}_{2} \mathrm{O}$ & 13.57 & 13.57 \\
$\mathrm{FeCl}_{3} \cdot 6 \mathrm{H}_{2} \mathrm{O}$ & 6.78 & 6.78 \\
$\mathrm{CaCl}_{2} .2 \mathrm{H}_{2} \mathrm{O}$ & 37.59 & 37.59 \\
$\mathrm{NaCl}$ & 48.05 & 48.05
\end{tabular}

Nishijima et al. (1993)

This can be seen from the biological removal percentage of COD which was high enough. For MLSS 15000 $\mathrm{mg} / \mathrm{l}$, the $\mathrm{F} / \mathrm{M}$ ratio was below the range of $0.2-0.6 \mathrm{~kg}$ $\mathrm{COD} / \mathrm{kg}$ MLSS day, consequently, the microorganisms present in the activated sludge can not develop well. When using normal activated sludge, the precipitation process runs slowly. However, with a membrane which is in one unit with Bioreactor, this is no longer an inhibitory. Hence, the SMBR performance remains good and stable in degrading the overall organic load. This is proven as the advantage of biological process compared to that of filtration process.

At MLSS of $8000 \mathrm{mg} / \mathrm{l}$ (high $\mathrm{F} / \mathrm{M}$ ratio), the COD removal by filtration and biological processes, did not show a significant difference at SRT of 10, 20, and 30 days, similarly, at MLSS of 15,000 mg/l (low F/M ratio) and at SRT of 10 and 20 days. However, COD removal by biological process increased at SRT of 30 days.

Fig. 4 shows the effect of the addition of PAC concentration on COD removal in SMBR for waste with high sludge concentration. A variety of PAC used in the experiment was $0 \%, 2.5 \%, 5 \%, 7.5 \%$, to $10 \%$, respectively at SRT of 30 days and at high MLSS of 15,000 (low F/M ratio) and COD of $2500 \mathrm{mg} / \mathrm{l}$.

\section{B. COD Removal of MLSS $(15,000 \mathrm{mg} / \mathrm{l})$ at Various $P A C$}

The results showed that the greater the concentration of PAC addition the better the COD removal occurred. With PAC addition of $10 \%$, the biological process was higher than that of with no PAC addition or with other PAC concentrations addition. (Munz and Gori, 2007). This was due to the adsorption process of organic materials by the PAC in the SMBR. In the biological process waste; the adsorption was not only carried out by microbes but also by PAC. As a result, the filtration process as a mechanism of membrane was slow when compared to that of in the non-PAC. The COD removal with PAC of $10 \%$ reached $91.86 \%$ compared to that of with other PAC. Hence, it can be said that the addition of PAC can improve the performance of SMBR process. This showed that the addition of PAC stabilize the performance of activated sludge in the SMBR to degrade the organic matter.
TABLE 4.

IDENTIFICATION OF MICROORGANISMS

\begin{tabular}{ccc}
\hline SRT & Treatment & $\begin{array}{l}\text { Number of } \\
\text { Bacteria }\end{array}$ \\
\hline & Non PAC & $1.80 \times 10^{7}$ \\
SRT 30 & PAC 2,5\% & $8.50 \times 10^{6}$ \\
& PAC 5\% & $7.75 \times 10^{6}$ \\
& PAC 7,5\% & $7.25 \times 10^{6}$ \\
& PAC 10\% & $5.00 \times 10^{6}$ \\
\hline
\end{tabular}

\section{Concentrations of SMP as Fouling Identification}

SMP is complex organic substances having different characteristics resulted from microbial metabolism products. SMP can plug membrane pores and cause membrane fouling. SMP can be classified into two groups; SMP as a product of substrate metabolism and growing biomass, and SMP as a product of dead biomass (Barker and Stuckey, 1999).

Fig. 5. indicates comparison of SMP concentrations at various SRT and MLSS variables, where the composition of SMP is stated as carbohydrate and protein. It was found that at MLSS of $8000 \mathrm{mg} / \mathrm{l}$, the amount of SMP for SRT of 10,20, and 30 days was fewer than that of at MLSS of $15000 \mathrm{mg} / \mathrm{l}$. This was due to the high MLSS concentration that led the amount of microorganisms contained in SMAHBR to increase compared with that of at low MLSS concentration; as a result, metabolic products of microorganisms also increased. Similarly, the amount of SMP decreased with the increase of SRT (Liang et al., 2007). The longer the SRT the longer the microorganisms stayed in the bioreactor; hence, the biodegradation process would work well. As a result, metabolism products of microorganisms would also decrease. When comparing the amount of SMP before and after the addition of PAC (Fig. 6), it shows that at PAC addition of $10 \%$ the amount of SMP was less than that of at PAC addition of other variables. At PAC addition of $10 \%$, the amount of SMP reduce up to $32-66 \%$. SMP adsorption by PAC resulted in the decrease of SMP concentration in the wastewater. According to Nicolas, et al. (2007), the addition of PAC in the submerged membrane system could reduce SMP concentration as a result of reduction of protein and carbohydrate concentrations in the supernatant, hence reducing the occurrence of fouling in the membrane.

Table 4. shows the amount of microorganisms. It appears that prior to the addition of PAC, the amount of microorganism was more than that after the addition of PAC. Table 4. also shows that the more PAC addition concentration was, the less the amount of microbes was. This shows that the addition of PAC led to reduced microorganisms in the reactor, as a result, microbial removal going well. This is due to PAC's ability to bind so small sized microbial substances (smaller than membrane pose diameter) on solid surfaces in a liquid phase that a gel layer was on the surface of PAC, which later would occur solid integration leading to the increase in the size of microbes, thus it become unable to pass through the membrane pores. As a result, a clearer effluent that did not contain microbes would be obtained. 


\section{CONCLUSION}

1. COD removal efficiency with $10 \%$ of the addition of $\mathrm{PAC}$ is $90-95 \%$.

2. High SMP accumulation $( \pm 10 \mathrm{mg} / \mathrm{l})$ occurred in short SRT (10 days) and high MLSS concentration $(15,000 \mathrm{mg} / \mathrm{l})$.

3. The addition of PAC led to reduced microorganisms in the reactor, as a result microbial removal could go well. For non PAC treatment, numbers of bacteria are $1.8 \times 10^{7}$, and for addition of $10 \%$ PAC, numbers of bacteria are $5.0 \times 10^{6}$.

\section{ACKNOWLEDGEMENT}

This project were sponsored by Fundamental Research -General Directorate of Higher Education (DP2M) 2009 by Grant: 10473/I2.7/PM/2009 and "Strategies ITS" Research, DIPA ITS 2009 by Grant: 10474/I2.7/PM/ 2009. The authors would like to thank : Dahlia I.C., Endah T., Voni Y., and Yulia R. for their contribution to this research.

\section{REFFERENCES}

[1] APHA, AWWA, and WEF, 1998, "Standard methods for the examination of water and wastewater", 17th ed., American Public Health Association, Washington DC.

[2] D. J. Barker and D. C. Stuckey, 1999, "A review of soluble microbial products (SMP) in waste water treatment systems", Water Research 33, (14), 3063-3082.

[3] K. Brindle and T. Stephenson, 1996, "The application of membrane biological reacrors for the treatment of wastewaters", Biotechnol, Bioeng, 49 (6), 601-610.

[4] B. D. Cho and A. G. Fane, 2002. "Fouling transients in nominally subcritical flux operation of a membrane bioreactor", Journal of Membrane Science, Vol. 209, 391-403.

[5] Dialynas and E. Diamadapoulos, 2008, "Integration of immersed membrane ultrafiltration with coagulation and activated carbon adsorption for advanced treatment of municipal wastewater", Desalination 230, 113-127.

[6] X. Juan Gai and H. S. Kim, 2008, "The role of powdered activated carbon in enhancing the peformance of membrane systems for water threatment", Desalination 225, 288-300.
[7] H. S. Kim, H. Katayama, S. Takizawa, and S. Ohgaki, 2001, "Removal of Coliphage Kibeta and Organic Matter from Synthetic Secondary Effluent by PAC- NF Process", Proc. IWA Specialized Conference on Membrane Technology, Israel, 211-219.

[8] Y. Liu, 2003, "Chemically reduced excess sludge production in the activated sludge process", Chemosphere 50, 1-7.

[9] S. Liang, C. Liu, and L. Song, 2007, "Soluble microbal products in membrane bioreactor operation: Behaviors, characteristics, and fouling potential", Water Research 41, 95-101.

[10] A. Masse, M. Sperandio, and C. Cabassud, 2006, "Comparison of sludge characteristics and performance of a submerged membrane bioreactor and an activated sludge process at high solids retention time", Water Research 40, 2405-2415.

[11] G. Munz and R. Gori, 2007, "Powdered Activated Carbon and Membrane Bioreactors (MBR-PAC) for tannery wastewater treatment: long term effect on biological and filtration process performance", Desalination 207, 349-360.

[12] H. Nagaoka, S. Ueda, and A. Miya, 1996, "Influence of bacterial extracellular polymers on the membrane separation activated sludge process", Water Science Technology 34, 165-172.

[13] L. Nicolas, M. Sperandio, and C. Cabassud, 2007, "Study of a hybrid process : Adsorption on activated carbon/membrane bioreactor for the treatment of an industrial wastewater", Chemical Engineering and Processing 47, 303-307.

[14] W. Nishijima, H. Itoh, M. Okada, A. Murakami, 1993, "Simultaneous removal of phenol and ammonium nitrogen by activated process added with biological support media and fixed-bed process", Water Enviroment 16, 284-290.

[15] K. Ouyang and L. Junxin, 2009. "Effect of sludge retention time on sludge characteristics and membrane fouling of membrane bioreactor", Journal of Eviromental Sciences 21, 1329-1335.

[16] Y. Satyawali and M. Balakrishnan, 2009, "Effect of PAC addition on sludge properties in an mbr treating high strength wastewater", Water Research 43, 1577 - 1588.

[17] D. W. Sundstrom and H. E. Klei, 1979, Wastewater Treatment, London : Prentice-Hall International, Inc.

[18] T. Widjaja, T. Miyata, W. Nakano, W. Nishijima, and M. Okada, 2004, "Adsorption capacity of powdered activated carbon for 3,5 dichlorophenol in activated carbon", Chemosphere 57, 12191224.

[19] K. Yamamoto, M. Hiasa, T. Mahmood, and T. Matsuo, 1989, "Direct solid liquid separation using hollow fiber membrane in an activated sludge aeration tank", Water Science Technology 21, 43-54.

[20] Z. Ying and G. Ping, 2006, "Effect of powdered activated carbon dosage on retarding membrane fouling in MBR", Separation and Purification Technology 52, 154-16. 